\title{
Bi-level Linear Fractional Programming Problem based on Fuzzy Goal Programming Approach
}

\author{
Surapati Pramanik \\ Department of Mathematics, Nandalal Ghosh \\ B.T. College, Panpur, Narayanpur \\ North 24 Parganas, Pin code-743126, West \\ Bengal, India
}

\author{
Partha Pratim Dey \\ Patipukur Pallisree Vidyapith, 1, Pallisree \\ Colony, Patipukur, Kolkata-700048 \\ West Bengal, India
}

\begin{abstract}
This paper presents fuzzy goal programming approach for bilevel linear fractional programming problem with a single decision maker at the upper level and a single decision maker at the lower level. Here, each level has single objective function, which are fractional in nature and the system constraints are linear functions. In the proposed approach, we first construct fractional membership functions by determining individual best solution of the objective functions subject to the system constraints. The fractional membership functions are then transformed into equivalent linear membership functions by first order Taylor polynomial series. Since the objectives of both level decision makers are potentially conflicting in nature, a possible relaxation of both level decisions is considered for avoiding decision deadlock. Then, the fuzzy goal programming approach is used for achieving highest degree of each of the membership goals to the maximum possible by minimizing the negative deviational variables. To demonstrate the efficiency of the proposed approach, an illustrative numerical example is solved and Euclidean distance function is used to obtain compromise optimal solution.
\end{abstract}

\section{General Terms}

Bi-level programming.

\section{Keywords}

Bi-level programming, Bi-level linear fractional programming, Fuzzy programming, Fuzzy goal programming.

\section{INTRODUCTION}

Bi-level programming problem (BLPP) [1-4] consists of two levels, namely, the upper level and the lower level with single objective at each level. The execution of decision is sequential from upper level to lower level and each decision maker (DM) independently controls a set of decision variables. Here, each DM independently optimizes his/her own benefits, but is affected by the action or reaction of the other DM. Candler and Townsley [3] as well as Fortuny-Amat and McCarl [4] presented the formal formulation of BLPP. Anandalingam [5] discussed mathematical programming model based on Stackelberg solution concept to multi-level programming problem (MLPP) as well as decentralized bi-level programming problem (DBLPP). Lai [6] introduced satisfactory solution concept based on fuzzy programming approach to MLPP by using tolerance membership function in 1996. Lai's satisfactory solution concept was extended by Shih et al. [7] by using noncompensatory max-min aggregation operator for solving
MLPPs. Shih and Lee [8] further extended Lai's concept by introducing the compensatory fuzzy operator for solving MLPPs. Sakawa et al. [9] have developed interactive fuzzy programming for MLPPs. Pramanik and Roy [10] discussed fuzzy goal programming (FGP) approach for solving MLPP. They [10] extended FGP to DBLPP.

In this article, we have considered bi-level linear fractional programming problem (BLFPP) with a single DM namely upper level decision maker (ULDM) at the upper level and a single DM namely lower level decision maker (LLDM) at the lower level. The objective functions of the DMs are linear fractional functions and the system constraints are linear functions.

Thirwani and Arora [11] discussed BLFPP in crisp environment in 1993. Sakawa and Nishizaki $[12,13]$ studied interactive fuzzy programming to BLFPP as well as decentralized BLFPP. Calvate and Galé [14, 15], Mishra [16] developed different approaches for solving BLFPP. M. Ahlatcioglu and F. Tirayaki [17] presented interactive fuzzy programming for solving a decentralized BLFPP by analytical hierarchy process. Malhotra and Arora [18] proposed an algorithm for solving BLFPP based on goal programming approach. I. A. Baky [19] discussed FGP algorithm for solving decentralized bi-level multi-objective programming problem by suitable variable transformation method. Toksar1 [20] used Taylor series approach for BLFPP. In this paper [20], the fractional objective functions are transformed into equivalent linear objective functions by using first order Taylor series. Then, the problem is solved by reducing BLFPP into single objective programming problem by assigning weights.

In the proposed approach, we first construct fractional membership functions by determining individual best solution of the objective functions subject to the system constraints. The fractional membership functions are then transformed into equivalent linear membership functions by first order Taylor polynomial series at the individual best solution point. Since the objectives are potentially conflicting in nature, decision deadlock arises frequently in the decision-making context. To avoid such situation, cooperation between both levels is needed. Let, the LLDM first provides his/her preference bounds on the decision variables under his/her control in the decision-making situation. Here, we consider the preference bounds of LLDM are fixed. Considering the preference bounds of the LLDM, the ULDM also provides his/her preference bounds on the decision variables under his/her control. The ULDM may vary his/her preference bounds to lead the solution in desired level. Then fuzzy goal programming approach is used for achieving highest 
degree of each of the membership goals to the extent possible by minimizing only the negative deviational variables. Euclidean distance function is then used to select the compromise optimal solution for both the DMs in the decision-making situation. A numerical example is provided in order to show the efficiency of the proposed approach.

Rest of the paper is organized as follows: section 2 presents the formulation of BLFPP. Section 3 provides fuzzy programming formulation of BLFPP. In subsection 3.1, we explain the linearization of the membership functions by first order Taylor series approximation. Subsection 3.2 provides characterization of preference bounds on the decision variables for both level DMs. In subsection 3.3, FGP model for BLFPP has been presented. Section 4 discusses the use of Euclidean distance function for the selection of compromise optimal solution. Section 5 provides the FGP algorithm for BLFPP. In section 6, we solve a numerical example to demonstrate the efficiency of the proposed approach. Section 7 contains the concluding remarks and future works.

\section{FORMULATION OF BLFPP}

We consider a BLFPP of maximization-type objective function at each level. Mathematically, the problem can be formulated as:

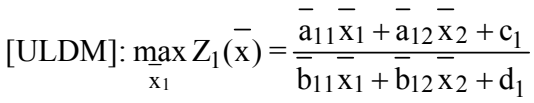

$[\mathrm{LLDM}]: \max _{\bar{x}_{2}} Z_{2}(\overline{\mathrm{x}})=\frac{\overline{\mathrm{a}}_{21} \overline{\mathrm{x}}_{1}+\overline{\mathrm{a}}_{22} \overline{\mathrm{x}}_{2}+\mathrm{c}_{2}}{\overline{\mathrm{b}}_{21} \overline{\mathrm{x}}_{1}+\overline{\mathrm{b}}_{22} \overline{\mathrm{x}}_{2}+\mathrm{d}_{2}}$

subject to

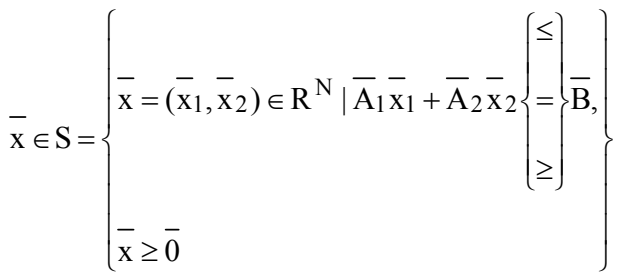

$\overline{\mathrm{x}}_{1}=\left\{\mathrm{x}_{11}, \mathrm{x}_{12}, \ldots, \mathrm{x}_{1 \mathrm{~N}_{1}}\right\}^{\mathrm{T}}:$ decision vector under the control of ULDM,

$\overline{\mathrm{x}}_{2}=\left\{\mathrm{x}_{21}, \mathrm{x}_{22}, \ldots, \mathrm{x}_{2 \mathrm{~N}_{2}}\right\}^{\mathrm{T}}:$ decision vector under the control of LLDM.

Here, $\bar{a}_{i 1}$ and $\bar{b}_{i 1}(i=1,2)$ are $\mathrm{N}_{1}$-dimensional row vectors; $\overline{\mathrm{a}}_{\mathrm{i} 2}$ and $\overline{\mathrm{b}}_{\mathrm{i} 2}(\mathrm{i}=1,2)$ are $\mathrm{N}_{2}$-dimensional row vectors; $\mathrm{c}_{\mathrm{i}}$ and $\mathrm{d}_{\mathrm{i}}$ $(\mathrm{i}=1,2)$ are constants. $\overline{\mathrm{A}}_{\mathrm{i}}(\mathrm{i}=1,2)$ is an $\mathrm{M} \times \mathrm{N}_{\mathrm{i}}$ constant matrix and $\bar{B}$ is an M-dimensional constant column vector. The symbol ' $\mathrm{T}$ ' denotes transposition. Here, $\mathrm{S}$ is assumed nonempty, convex and compact in $\mathrm{R}^{\mathrm{N}}$. We also assume that the denominators of the objective functions are positive, i.e. $\overline{\mathrm{b}}_{\mathrm{i} 1} \overline{\mathrm{x}}_{1}+\overline{\mathrm{b}}_{\mathrm{i} 2} \overline{\mathrm{x}}_{2}+\mathrm{d}_{\mathrm{i}}>\overline{0} \quad(\mathrm{i}=1,2)$.

\section{FUZZY \\ PROGRAMMING FORMULATION OF BLFPP}

To formulate the fuzzy programming model of a BLFPP, the objective functions would be transformed into fuzzy goals by means of introducing an imprecise aspiration level to each of the objectives.

The optimal solution of the objective function $Z_{i}(i=1,2)$ when calculated in isolation would be considered as the best solution and associated objective value can be considered as the aspiration of the corresponding fuzzy goal.

Let, $\quad \mathrm{x}_{\mathrm{i}}^{\mathrm{B}}=\left(\mathrm{x}_{\mathrm{i} 1}^{\mathrm{B}}, \mathrm{x}_{\mathrm{i} 2}^{\mathrm{B}}, \ldots, \mathrm{x}_{\mathrm{iN}_{\mathrm{i}}}^{\mathrm{B}}, \mathrm{x}_{\mathrm{iN}_{\mathrm{i}}+1}^{\mathrm{B}}, \ldots, \mathrm{x}_{\mathrm{iN}}^{\mathrm{B}}\right)(\mathrm{i}=1,2)$ be the individual best solution of the objective function of $\mathrm{i}$-th level DM subject to the system constraints.

Also let, $\mathrm{Z}_{\mathrm{i}}^{\mathrm{B}}=\mathrm{Z}_{\mathrm{i}}\left(\overline{\mathrm{x}}_{\mathrm{i}}^{\mathrm{B}}\right)=\max _{\overline{\mathrm{x}} \in \mathrm{S}} \mathrm{Z}_{\mathrm{i}}(\overline{\mathrm{x}})(\mathrm{i}=1,2)$

It is obvious that objective value which are equal to or larger than $Z_{i}^{B}(\bar{x})(i=1,2)$ should be absolutely satisfactory to each level DM.

Then the fuzzy goal of the objective function of the DM appears as follows:

$\mathrm{Z}_{\mathrm{i}}(\overline{\mathrm{x}}) \geq \mathrm{Z}_{\mathrm{i}}^{\mathrm{B}}(\mathrm{i}=1,2)$.

Here, " $\geq$ " indicates the fuzziness of the aspiration level and it is described as "essentially greater than".

To build the membership functions, upper tolerance limit and lower tolerance limit should be determined first. Using the individual best solutions, we find the values of the objective functions at each best solution and construct a payoff matrix as:

$$
\left[\begin{array}{ccc} 
& \mathrm{Z}_{1}(\overline{\mathrm{x}}) & \mathrm{Z}_{2}(\overline{\mathrm{x}}) \\
-\mathrm{B} & \mathrm{Z}_{1}(\overline{\mathrm{x}} 1) & \mathrm{Z}_{2}(\overline{\mathrm{x}} 1) \\
\mathrm{x}_{1} & \mathrm{~B}_{2}\left(\overline{\mathrm{B}}_{2}\right) & \mathrm{Z}_{2}\left(\overline{\mathrm{x}}_{2}\right)
\end{array}\right]
$$

The maximum value of each column $Z_{i}(\bar{x})(i=1,2)$ gives upper tolerance limit or aspired level of achievement for i-th objective function i.e.

$$
Z_{i}^{B}=Z_{i}\left(\bar{x}_{i}^{B}\right)=\max _{x \in S} Z_{i}(\bar{x})(i=1,2)
$$

The minimum value of each column gives lower tolerance limit or lowest acceptable level of achievement for i-th objective function i.e.

$\mathrm{Z}_{\mathrm{i}}^{\mathrm{W}}=\min \left\{\mathrm{Z}_{\mathrm{i}}\left(\begin{array}{c}-\mathrm{B} \\ \mathrm{x}_{1}\end{array}\right), \mathrm{Z}_{\mathrm{i}}\left(\begin{array}{c}-\mathrm{B} \\ \mathrm{x}_{2}\end{array}\right)\right\}(\mathrm{i}=1,2)$. 
Then, membership function $\mu_{\mathrm{i}}(\mathrm{i}=1,2)$ for $\mathrm{i}$-th fuzzy goal can be formulated as:

$$
\mu_{i}=\left\{\begin{array}{ll}
1, & \text { if } Z_{i}(\bar{x}) \geq Z_{i}^{B} \\
\frac{Z_{i}(\bar{x})-Z_{i}^{W}}{Z_{i}^{\mathrm{B}}-Z_{i}^{W}}, & \text { if } Z_{i}^{W} \leq Z_{i}(\bar{x}) \leq Z_{i}^{B} \\
0, & \text { if } Z_{i}(\bar{x}) \leq Z_{i}^{W}
\end{array}\right\} \quad(i=1,2)
$$

Here, $Z_{i}^{\mathrm{B}}$ and $\mathrm{Z}_{\mathrm{i}}^{\mathrm{W}}(\mathrm{i}=1,2)$ are respectively the upper and lower tolerance limits of the fuzzy goal of $\mathrm{i}$-th objective functon.

\subsection{Linearization of fractional membership functions by Taylor series approximation}

Let, $\bar{x}_{\mathrm{i}}^{*}=\left(\mathrm{x}_{\mathrm{i} 1}^{*}, \mathrm{x}_{\mathrm{i} 2}^{*}, \ldots, \mathrm{x}_{\mathrm{iN}_{\mathrm{i}}}^{*}, \mathrm{x}_{\mathrm{iN}_{\mathrm{i}}+1}^{*}, \ldots, \mathrm{x}_{\mathrm{iN}}^{*}\right)$ be the individual best solution of $i$-th fractional membership function $\mu_{i}(\bar{x})(i=1,2)$ subject to the system constraints. Next, we transform the fractional membership function $\mu_{\mathrm{i}}(\overline{\mathrm{x}}) \quad(\mathrm{i}=1,2)$ into an equivalent linear membership function $\xi_{\mathrm{i}}(\overline{\mathrm{x}})$ at $\bar{x}_{\mathrm{i}}^{*}=\left(\mathrm{x}_{\mathrm{i} 1}^{*}, \mathrm{x}_{\mathrm{i} 2}^{*}, \ldots, \mathrm{x}_{\mathrm{iN}_{\mathrm{i}}}^{*}, \mathrm{x}_{\mathrm{iN}_{\mathrm{i}}+1}^{*}, \ldots, \mathrm{x}_{\mathrm{iN}}^{*}\right)$ by first order Taylor series approximation as follows:

$$
\begin{aligned}
& \mu_{\mathrm{i}}(\overline{\mathrm{x}}) \cong \mu_{\mathrm{i}}\left(\overline{\mathrm{x}}_{\mathrm{i}}^{*}\right)+\left(\mathrm{x}_{1}-\mathrm{x}_{\mathrm{i} 1}^{*}\right) \frac{\partial \mu_{\mathrm{i}}\left(\overline{\mathrm{x}}_{\mathrm{i}}^{*}\right)}{\partial \mathrm{x}_{1}}+\left(\mathrm{x}_{2}-\mathrm{x}_{\mathrm{i} 2}^{*}\right) \frac{\partial \mu_{\mathrm{i}}\left(\overline{\mathrm{x}}_{\mathrm{i}}^{*}\right)}{\partial \mathrm{x}_{2}}+\ldots \\
& +\left(\mathrm{x}_{\mathrm{N}_{\mathrm{i}}}-\mathrm{x}_{\mathrm{iN}}^{*}\right) \frac{\partial \mu_{\mathrm{i}}\left(\overline{\mathrm{x}}_{\mathrm{i}}^{*}\right)}{\partial \mathrm{x}_{\mathrm{N}_{\mathrm{i}}}}+\left(\mathrm{x}_{\mathrm{N}_{\mathrm{i}}+1}-\mathrm{x}_{\mathrm{iN}_{\mathrm{i}}+1}^{*}\right) \frac{\partial \mu_{\mathrm{i}}\left(\overline{\mathrm{x}}_{\mathrm{i}}^{*}\right)}{\partial \mathrm{x}_{\mathrm{N}_{\mathrm{i}}+1}}+\ldots+ \\
& \left(\mathrm{x}_{\mathrm{N}}-\mathrm{x}_{\mathrm{iN}}^{*}\right) \frac{\partial \mu_{\mathrm{i}}\left(\overline{\mathrm{x}}_{\mathrm{i}}^{*}\right)}{\partial \mathrm{x}_{\mathrm{N}}}=\xi_{\mathrm{i}}(\overline{\mathrm{x}})(\mathrm{i}=1,2)
\end{aligned}
$$

\subsection{Characterization of preference bounds on the decision variables}

Since the individual best solution of the DMs are different, cooperation between the DMs is necessary to reach a compromise optimal solution. We consider that the LLDM sets his/her decision first by providing fixed preference bounds on the decision variables under his/her control according to his/her needs and desires in the practical decision-making situation.

Let, $\bar{x}_{2}^{*}=\left(x_{21}^{*}, x_{22}^{*}, \ldots, x_{2 N_{2}}^{*}, x_{2 N_{2}+1}^{*}, \ldots, x_{2 N}^{*}\right)$ be the individual best solution of the membership function $\mu_{2}(\bar{x})$ of LLDM when calculated in isolation. Also let, $\left(x_{2 i}^{*}-\alpha_{2 \mathrm{i}}^{-}\right)$and $\left(x_{2 i}^{*}+\alpha_{2 i}^{+}\right)\left(i=1,2, \ldots, N_{2}\right)$ be the lower and upper bounds of decision variables $\mathrm{x}_{2 \mathrm{i}}\left(\mathrm{i}=1,2, \ldots, \mathrm{N}_{2}\right)$ provided by the LLDM.

Here, $\alpha_{2 \mathrm{i}}^{-}$and $\alpha_{2 \mathrm{i}}^{+}\left(\mathrm{i}=1,2, \ldots, \mathrm{N}_{2}\right)$ are the negative and positive tolerance variables which are not necessarily same. Generally, $x_{2 i}$ lies between $\left(x_{2 i}^{*}-\alpha_{2 i}^{-}\right)$and $\left(x_{2 i}^{*}+\alpha_{2 i}^{+}\right)(i=1$,
$2, \ldots, \mathrm{N}_{2}$ ). Considering the decision of LLDM, the ULDM should take necessary steps by providing preference bounds on the decision variables under his/her control. Let, $\bar{x}_{1}^{*}=\left(x_{11}^{*}, x_{12}^{*}, \ldots, x_{1 N_{1}}^{*}, x_{1 N_{1}+1}^{*}, \ldots, x_{1 N}^{*}\right)$ be the individual best solution of the linear membership function of UDLM when calculated in isolation. Also let, $\left(\mathrm{x}_{1 \mathrm{i}}^{*}-\alpha_{1 \mathrm{i}}^{-}\right)$and $\left(\mathrm{x}_{1 \mathrm{i}}^{*}+\alpha_{1 \mathrm{i}}^{+}\right)(\mathrm{i}=1$, $2, \ldots, N_{1}$ ) be the lower and upper bounds of decision variable $\mathrm{x}_{1 \mathrm{i}}$ $\left(\mathrm{i}=1,2, \ldots, \mathrm{N}_{1}\right)$ provided by the ULDM. Here, the positive and negative tolerance variables under the control of ULDM should be defined as above. However, it is to be noted that the ULDM may vary his/her preference bounds considering overall benefit of the organization. Therefore, we can write

$$
\begin{aligned}
& \left(\mathrm{x}_{1 \mathrm{i}}^{*}-\alpha_{1 \mathrm{i}}^{*}\right) \leq \mathrm{x}_{1 \mathrm{i}} \leq\left(\mathrm{x}_{1 \mathrm{i}}^{*}+\alpha_{1 \mathrm{i}}^{*}\right) \quad\left(\mathrm{i}=1,2, \ldots, \mathrm{N}_{1}\right) \\
& \left(\mathrm{x}_{2 \mathrm{i}}^{*}-\alpha_{2 \mathrm{i}}^{*}\right) \leq \mathrm{x}_{2 \mathrm{i}} \leq\left(\mathrm{x}_{2 \mathrm{i}}^{*}+\alpha_{2 \mathrm{i}}^{*}\right) \quad\left(\mathrm{i}=1,2, \ldots, \mathrm{N}_{2}\right)
\end{aligned}
$$

\subsection{Formulation of FGP model of BLFPP}

The BLFPP represented in section 2 reduces to the following problem

$\max \left\{\xi_{\mathrm{i}}(\overline{\mathrm{x}})\right\} \quad(\mathrm{i}=1,2)$

subject to

$$
\begin{aligned}
& \bar{x} \in S=\left\{\begin{array}{l}
\bar{x}=\left(\bar{x}_{1}, \bar{x}_{2}\right) \in R^{N} \mid \bar{A}_{1} \bar{x}_{1}+\bar{A}_{2} \bar{x}_{2}\left\{=\left\{\begin{array}{l}
\leq \\
\bar{B} \\
z
\end{array}\right\},\right. \\
\bar{x} \geq \overline{0}
\end{array}\right\} \\
& \left(x_{1 i}^{*}-\alpha_{1 i}^{*}\right) \leq x_{1 i} \leq\left(x_{1 i}^{*}+\alpha_{1 i}^{*}\right),\left(i=1,2, \ldots, N_{1}\right) \\
& \left(x_{2 i}^{*}-\alpha_{2 i}^{*}\right) \leq x_{2 i} \leq\left(x_{2 i}^{*}+\alpha_{2 i}^{*}\right) \quad\left(i=1,2, \ldots, N_{2}\right)
\end{aligned}
$$

Since the maximum value of a membership function is unity, so for the defined membership function in (11), the flexible membership goals having the aspiration level unity can be formulated as:

$\xi_{i}(\bar{x})+d_{i}^{-}-d_{i}^{+}=1(i=1,2)$

Here, $d_{i}^{-}(\geq 0)(i=1,2)$ represents the negative deviational variable and $\mathrm{d}_{\mathrm{i}}^{+}(\geq 0) \quad(\mathrm{i}=1,2)$ represents the positive deviational variable. It may be noted that any over deviation from a fuzzy goal indicates the full achievement of the membership value. Then, according to Pramanik and Roy [10], (12) can be represented as follows:

$\xi_{i}(\bar{x})+d_{i}^{-} \geq 1(i=1,2)$ 
Then the FGP model for solving BLFPP can be explicitly formulated as:

$\min =\sum_{i=1}^{2} d_{i}^{-}$

subject to

$\mu_{i}\left(\bar{x}_{i}^{*}\right)+\left(x_{1}-x_{i 1}^{*}\right) \frac{\partial \mu_{i}\left(\bar{x}_{i}^{*}\right)}{\partial x_{1}}+\left(x_{2}-x_{i 2}^{*}\right) \frac{\partial \mu_{i}\left(\bar{x}_{i}^{*}\right)}{\partial x_{2}}+\ldots+$

$\left(\mathrm{x}_{\mathrm{N}_{\mathrm{i}}}-\mathrm{x}_{\mathrm{iN}_{\mathrm{i}}}^{*}\right) \frac{\partial \mu_{\mathrm{i}}\left(\mathrm{x}_{\mathrm{i}}^{*}\right)}{\partial \mathrm{x}_{\mathrm{N}_{\mathrm{i}}}}+\left(\mathrm{x}_{\mathrm{N}_{\mathrm{i}}+1}-\mathrm{x}_{\mathrm{iN}_{\mathrm{i}}+1}^{*}\right) \frac{\partial \mu_{\mathrm{i}}\left(\mathrm{x}_{\mathrm{i}}^{*}\right)}{\partial \mathrm{x}_{\mathrm{N}_{\mathrm{i}}+1}}+\ldots+$

$\left(\mathrm{x}_{\mathrm{N}}-\mathrm{x}_{\mathrm{N} N}^{*}\right) \frac{\partial \mu_{\mathrm{i}}\left(\overline{\mathrm{x}}_{\mathrm{i}}^{*}\right)}{\partial \mathrm{x}_{\mathrm{N}}}+\mathrm{d}_{\mathrm{i}}^{-} \geq 1,(\mathrm{i}=1,2)$

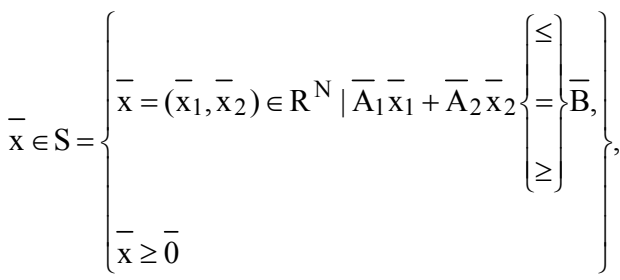

$\left(x_{1 i}^{*}-\alpha_{1 i}^{*}\right) \leq x_{1 i} \leq\left(x_{1 i}^{*}+\alpha_{1 i}^{*}\right),\left(i=1,2, \ldots, N_{1}\right)$

$\left(x_{2 i}^{*}-\alpha_{2 i}^{*}\right) \leq x_{2 i} \leq\left(x_{2 i}^{*}+\alpha_{2 i}^{*}\right),\left(i=1,2, \ldots, N_{2}\right)$

$\mathrm{d}_{\mathrm{i}}^{-} \geq 0(\mathrm{i}=1,2)$

\section{USE OF DISTANCE FUNCTION FOR SELECTING COMPROMISE OPTIMAL SOLUTION}

$\mathrm{Yu}$ [21] studied the use of distance function for group decision analysis based on the concept of utopia point (the ideal point) solution at first in 1973. In the FGP formulation, since the aspired level of each of the membership goals is unity (one), the point consists of the highest membership value of each of the goals would represent the ideal point. The Euclidean distance function is formulated as:

$\mathrm{D}_{2}=\left[\sum_{\mathrm{t}=1}^{\mathrm{K}}\left[1-\mu_{\mathrm{t}}(\overline{\mathrm{x}})\right]^{2}\right]^{1 / 2}$

Here, $\mu_{\mathrm{t}}(\overline{\mathrm{x}})$ represents the achieved membership value of the $\mathrm{t}$ th objective goal. The solution for which $\mathrm{D}_{2}$ is minimal would be the most satisfycing solution.

\section{THE FGP \\ ALGORITHM \\ FOR} SOLVING BLFPP

The solution algorithm for solving BLFPP is given in the following steps

Step 1: Determine the individual best solution $\mathrm{x}_{\mathrm{i}}=$ $\left(x_{i 1}^{B}, x_{i 2}^{B}, \ldots, x_{i N_{i}}^{B}, x_{i N_{i}+1}^{B}, \ldots, x_{i N}^{B}\right)(i=1,2)$ of each objective function subject to the system constraints as given by (2).

Step 2: Construct the payoff matrix as given by (3). Then define upper tolerance limit and lower tolerance limit of each objective function as given by (5) \& (6).

Step 3: Construct the fractional membership function $\mu_{\mathrm{i}}(\overline{\mathrm{x}})(\mathrm{i}=$ $1,2)$ of the objective function $Z_{i}(\bar{x})(i=1,2)$ as given by $(7)$.

Step 4: Find the individual best solution $\bar{x}_{\mathrm{i}}^{*}=\left(\mathrm{x}_{\mathrm{i} 1}^{*}, \mathrm{x}_{\mathrm{i} 2}^{*}, \ldots, \mathrm{x}_{\mathrm{iN}_{\mathrm{i}}}^{*}, \mathrm{x}_{\mathrm{iN}_{\mathrm{i}}+1}^{*}, \ldots, \mathrm{x}_{\mathrm{iN}}^{*}\right)$ of the fractional membership function $\mu_{\mathrm{i}}(\overline{\mathrm{x}})(\mathrm{i}=1,2)$ subject to the system constraints as given by (2).

Step 5: Transform the fractional membership function $\mu_{\mathrm{i}}(\overline{\mathrm{x}})(\mathrm{i}$ $=1,2)$ into an equivalent linear membership function $\xi_{\mathrm{i}}(\overline{\mathrm{x}}) \quad(\mathrm{i}=$ $1,2)$ at $\bar{x}_{\mathrm{i}}^{*}=\left(\mathrm{x}_{\mathrm{i} 1}^{*}, \mathrm{x}_{\mathrm{i} 2}^{*}, \ldots, \mathrm{x}_{\mathrm{iN}_{\mathrm{i}}}^{*}, \mathrm{x}_{\mathrm{iN}_{\mathrm{i}}+1}^{*}, \ldots, \mathrm{x}_{\mathrm{iN}}^{*}\right)(\mathrm{i}=1,2)$ by first order Taylor series approximation as given by $(8)$.

Step 6: The LLDM first provides preference bounds on the decision variables under his/her control. Then, considering fixed preference bounds of LLDM, the ULDM provides preference bounds on the decision variables under his/her control as given by (9) \& (10).

Step 7: Formulate the FGP model (14) for the BLFPP.

Step 8: Solve the problem (14) FGP model.

Step 9: Euclidean distance function is used to identify the compromise optimal solution. If the solution is acceptable to ULDM, then compromise optimal solution is reached. Otherwise, the ULDM provides another set of preference bounds on the decision variables under his/her control to reach compromise optimal solution.

Step 10: End.

\section{NUMERICAL EXAMPLE}

The following example is considered to demonstrate the efficiency of the proposed FGP approach:

$\max \mathrm{Z}_{1}(\mathrm{x})=\frac{\mathrm{x}_{1}+2 \mathrm{x}_{2}+2}{\mathrm{x}_{1}+\mathrm{x}_{2}+1}$ 
$\max \mathrm{Z}_{1}(\mathrm{x})=\frac{2 \mathrm{x}_{1}+\mathrm{x}_{2}-1}{\mathrm{x}_{1}+2 \mathrm{x}_{2}+3}$

subject to

$-\mathrm{x}_{1}+2 \mathrm{x}_{2} \leq 3$

$2 x_{1}-3 x_{2} \leq 3$

$\mathrm{x}_{1}+\mathrm{x}_{2} \geq 3$

$\mathrm{x}_{1} \geq 0, \mathrm{x}_{2} \geq 0$.

We find individual best solution subject as $Z_{1}^{\mathrm{B}}=1.75$ at $(1,2)$; $\mathrm{Z}_{2}^{\mathrm{B}}=1.056$ at $(15,9)$.

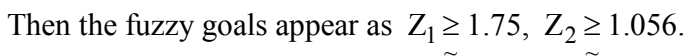

Payoff matrix $=\left[\begin{array}{cc}1.75 & 0.375 \\ 1.4 & 1.056\end{array}\right]$

Here, $Z_{1}^{\mathrm{B}}=1.75, \mathrm{Z}_{1}^{\mathrm{W}}=1.4 ; \mathrm{Z}_{2}^{\mathrm{B}}=1.056, \mathrm{Z}_{2}^{\mathrm{W}}=0.375$.

The fractional membership functions are as follows:

$\mu_{1}(x)=\frac{Z_{1}(x)-1.4}{1.75-1.4}=\frac{\frac{x_{1}+2 x_{2}+2}{x_{1}+x_{2}+1}-1.4}{1.75-1.4}$

$\mu_{2}(x)=\frac{Z_{2}(x)-0.375}{1.056-0.375}=\frac{\frac{2 x_{1}+x_{2}-1}{x_{1}+2 x_{2}+3}-0.375}{1.056-0.375}$

The fractional membership functions $\mu_{1}(\mathrm{x})$ and $\mu_{2}(\mathrm{x})$ are maximum at the points $(1,2),(15,9)$ respectively, subject to the system constraints.

The fractional membership functions are then transformed into equivalent linear membership functions $\xi_{\mathrm{i}}(\mathrm{x})(\mathrm{i}=1,2)$ at the individual best solution point by first order Taylor series approximation as follows:

$\xi_{1}(\mathrm{x})=\mu_{1}(1,2)+\left(\mathrm{x}_{1}-1\right) \frac{\partial \mu_{1}(1,2)}{\partial \mathrm{x}_{1}}+\left(\mathrm{x}_{2}-2\right) \frac{\partial \mu_{1}(1,2)}{\partial \mathrm{x}_{2}}$

$=1+\left(\mathrm{x}_{1}-1\right) \times(-0.536)+\left(\mathrm{x}_{2}-2\right) \times 0.178$, $\xi_{2}(\mathrm{x})=\mu_{2}(15,9)+\left(\mathrm{x}_{1}-15\right) \frac{\partial \mu_{2}(15,9)}{\partial \mathrm{x}_{1}}+\left(\mathrm{x}_{2}-9\right) \frac{\partial \mu_{2}(15,9)}{\partial \mathrm{x}_{2}}$

$=1+\left(\mathrm{x}_{1}-15\right) \times 0.038+\left(\mathrm{x}_{2}-9\right) \times(-0.045)$

Let, the fixed preference bound provided by LLDM be $2 \leq x_{2} \leq 16$. Considering the preference bound of the LLDM, the ULDM also provides preference bound for avoiding decision deadlock.

Then FGP formulation for solving BLFPP can be formulated as

$\min =\sum_{i=1}^{2} d_{i}^{-}$

subject to

$$
\begin{aligned}
& 1+\left(x_{1}-1\right) \times(-0.536)+\left(x_{2}-2\right) \times 0.178+d_{1}^{-} \geq 1 \\
& 1+\left(x_{1}-15\right) \times 0.038+\left(x_{2}-9\right) \times(-0.045)+d_{2}^{-} \geq 1 \\
& -x_{1}+2 x_{2} \leq 3 \\
& 2 x_{1}-3 x_{2} \leq 3 \\
& x_{1}+x_{2} \geq 3 \\
& 2 \leq x_{2} \leq 16 \\
& x_{1} \geq 0, x_{2} \geq 0 . \\
& d_{i}^{-} \geq 0,(i=1,2) .
\end{aligned}
$$

The results, obtained by different preference bounds provided by ULDM are shown in the Table 1.

Now from the Table 1, we observe that the minimum Euclidean distance value is 0.766 . The optimal compromise solution corresponding to the preference bound $3 \leq x_{1} \leq 7$ of ULDM is given by $Z_{1}(x)=1.571, Z_{2}(x)=0.667$ at $x_{1}=3, x_{2}=3$. The resulting membership values are $\mu_{1}(\mathrm{x})=0.49, \mu_{2}(\mathrm{x})=0.428$.

Note: All solutions of the problem are obtained by using the software Lingo, version 6.0. 
Table 1 Comparison of optimal solutions based on Euclidean distance function

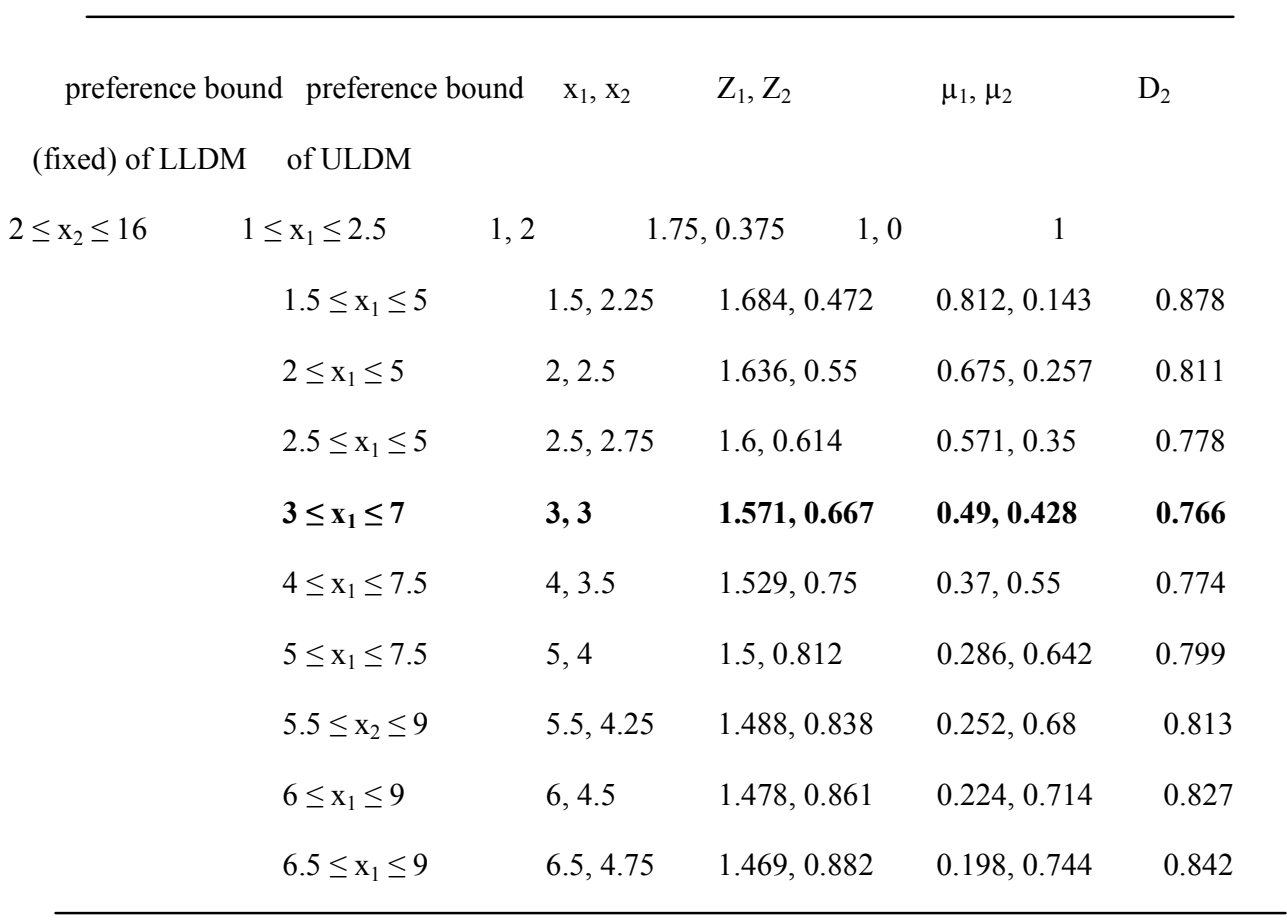

\section{CONCLUSION}

An alternative FGP approach for solving BLFPP based on first order Taylor series approximation is presented in this paper. In the proposed approach, the fractional membership functions corresponding to the objective functions are transformed into equivalent linear membership functions by first order Taylor series approximation. Preference bounds provided by both DMs are considered for practical decision-making problems. FGP approach is used to solve the problem by minimizing only negative deviational variables. Then, the Euclidean distance function is used to identify the compromise optimal solution. We can apply the concept to decentralized bi-level multiobjective and multi-level multi-objective fractional programming problems based on real-life decision-making problems.

\section{ACKNOWLEDGMENTS}

The authors are very grateful to the anonymous referees for their comments and suggestions, which have led to improve the quality and presentation of the paper to its current standard.

\section{REFERENCES}

[1] Bard, J. F. 1984. Optimality conditions for the bilevel programming problem. Naval Research Logistics Quarterly 31, 13-26.

[2] Bialas, W. F., and Karwan, M. H. 1984. Two level linear programming. Management Science 30, 1004-1020.
[3] Candler, W., and Townsley, R. 1982. A linear two-level programming problem. Computers \& Operations Research 9, 59-76.

[4] Fortuni-Amat, J., and McCarl, B. 1981. A representation and economic interpretation of a two-level programming problem. Journal of Operational Research Society 32, 783-792.

[5] Anandalingam, G. 1988. A mathematical programming model of decentralized multi-level systems. Journal of the Operational Research Society 39 (11), 1021-1033.

[6] Lai, Y. J. 1996. Hierarchical optimization: a satisfactory solution. Fuzzy Sets and Systems 77, 321-335.

[7] Shih, H. S., Lai, Y. J., and Lee, E. S. 1996. Fuzzy approach for multi-level programming problem. Computers \& Operations Research 23 (1), 73-91.

[8] Shih, H. S., and Lee, E. S. 2000. Compensatory fuzzy multiple level decision making. Fuzzy Sets and Systems 114, 71-87.

[9] Sakawa, M., and Nishizaki, I., and Uemura, Y. 1998. Interactive fuzzy programming for multilevel linear programming problems. Computers and Mathematics with Applications 36, 71-86.

[10] Pramanik, S., and Roy, T. K. 2007. Fuzzy goal programming approach to multi-level programming problems. European Journal of Operational Research 176, 1151-1166. 
[11] Thirwani, D., and Arora, S. R. 1993. Bi-level linear fractional programming problem. Cahiers Du Cero 35 (12), 135-149.

[12] Sakawa, M., and Nishizaki, I. 2002. Interactive fuzzy programming for decentralized two-level linear fractional programming problem. Fuzzy Sets and Systems 125, 301315.

[13] Sakawa, M., and Nishizaki, I. 2001. Interactive fuzzy programming for two-level linear fractional programming problem. Fuzzy Sets and Systems 119, 31-40.

[14] Calvete, H. I., and Galé, C. 2004. A note on bi-level linear fractional programming problem. European Journal of Operational Research 152, 296-299.

[15] Calvete, H. I., and Galé, C. 1999. The bi-level linear/linear fractional programming problem. European Journal of Operational Research 114, 188-197.

[16] Mishra, S. 2007. Weighting method for bi-level linear fractional programming problems 183, 296-302.
[17] Ahlatcioglu, M., and Tirayaki, F. 2007. Interactive fuzzy programming for decentralized two-level linear programming problems (DTLLFP). Omega 35, 432-450.

[18] Malhotra, N., and Arora, S. R. 2000. An algorithm to solve linear fractional bilevel programming problem via goal programming. Journal of the Operational Research Society of India (OPSEARCH) 37 (1), 1-13.

[19] Baky, I. A. 2009. Fuzzy goal programming algorithm for solving decentralized bi-level multi-objective programming problems. Fuzzy Sets and Systems 160, $2701-2713$

[20] Toksar1, M. D. 2010. Taylor series approach for bi-level linear fractional programming problem. Selçuk Journal of Applied Mathematics 11 (1) 63-69.

[21] Yu, P. L. 1973. A class of solutions for group decision problems. Management Science 19, 936-946. 